\title{
ADAPTATION OF MUSLIM FAMILY ACTIVITY IN OCCUPYING MINIMALIST CONTEMPORARY ARCHITECTURAL HOUSING DESIGN
}

Received February $14^{\text {th }}, 2020 \mid$ Accepted April 15th, 2020 | Available online December 15th, 2020

| DOI http://dx. doi.org/10.18860/jia.v6i2.8259 |

\section{Dwira Nirfalini Aulia}

Departemen Arsitektur

Universitas Sumatera Utara

Medan, Sumatera Utara, Indonesia

dwira.nirfalini@usu.ac.id

\section{Abdul Rahman Syafikri}

Departemen Arsitektur

Universitas Sumatera Utara

Medan, Sumatera Utara, Indonesia

abdulpauks@gmail.com

\begin{abstract}
The Muslim family's important criteria that inhabited their house are the needs of his family's privacy, creating an Islamic behavior (modesty) and entertaining guests (hospitality) who came to visit. The perception of these needs included the development of a minimalist contemporary architecture that is now widely grown. Contemporary minimalism is one type of architecture emerged in Indonesia, especially in Medan. The type is simple and small dimensions characterize minimalism. Does every Muslim family in the area of Medan (sample) is easily adaptable to the needs that exist in minimalist contemporary architecture include the need for privacy, modesty, and hospitality?. Therefore, the research purpose is to discover a Muslim family adaptation to the needs of space and performance. The method used was a qualitative method of mapping the behavior by place-centered mapping. Results from this study are the adaptation of living in the house to appropriate their needs and recommending improvements in the design of houses
\end{abstract}

KEYWORDS:

Adaptation, activity, Muslim family, minimalist housing design

\section{INTRODUCTION}

As an essential all Muslim activity, houses and domestic furnishings have deep significance than just a place for shelter in Islam [1]. In the development of the Post-Modern Architecture era, the phenomenon of minimalism in architecture is growing. Some researchers describe Minimalism in Architecture as simple and traditional shapes, geometric, unity, and simplicity [2][3]. The phenomenon of minimalism in architecture also occurs in Indonesia. It can be seen from the preferences of housing consumers towards minimalist architecture in some researches [4][5]. Based on this background, this research was carried out because, based on housing consumers' preferences, the developers, as housing producers, built planned housing with the concept of minimalist architecture. In the design of a home, minimalist contemporary style is a design concept in demand by Indonesian people, including in Medan. The number of Muslim families in need of house based on worship and the internalization of Islamic values need to be fulfilled to maintain good relations with nature and surroundings.

Architecture must be experienced to be understood. The complexity of the experience is seen through a better understanding of the relationship between architecture and human life [6]. Family experience in inhabiting minimalist buildings is a way to understand minimalist architecture itself. Minimalist architectural characteristics such as simple, geometric, unity, and simplicity require adjusting for the inhabiting family. Because there is a close relationship between the size of living space and subjective well-being [7]. The process of self-adjustment is an adaptation process. The process of adaptation can be grouped into three kinds; (1) adaptation by adjustment, (2) adaptation by the reaction, and (3) adaptation by withdrawal [8]. This research was conducted to determine the adaptation process carried out by Muslim families to minimalist residential buildings. The activities of inhabiting Muslim families have specific characteristics based on Islamic religious rules.

There are at least four criteria that need to be obeyed by an Islamic dwelling: separation between men and women without any marital relations, Islamic environment, and not to use the services of conventional financial institutions [9]. Are the Muslim families adaptable to contemporary minimalist dwelling to meet their needs, and performance space has been sufficient? The contemporary minimalist house is known for the character of a practical and functional design with geometric shapes that emphasize the space's processing efficiency. The research purpose is to discover a Muslim family adaptation living in minimalist contemporary 
architectural housing in Medan City.

In line with the increasing Muslim population in Indonesia, housing with the Islamic concept is also developing [9][10][11][12]. Then the needs of Muslim families for housing with the Islamic concept also increase. This research was conducted to examine whether minimalist housing can answer Muslim families' needs for the concept of Islamic housing.

Occupancy of a Muslim has the capacity as a cultural space and the social relevance of the Islamization of the area. Occupancy function as selfdevelopment by demonstrating the expression of emotions and social housing. On the other hand, it serves to share, entertain, build relationships, and physical occupancy function to its inhabitants as a physical structure, space, and architectural style. The relationship between the home occupied by Muslim families, the setting up of individuals, and the sense of interior space in the house is influenced by several factors such as religion and culture [13].

Privacy is regarded as very important thing in Muslim homes design that is determined by the teachings and traditions of Islam from two primary sources: a) The Quran - the revelation of Allah (God) to the Prophet Muhammad; and b) the Sunnah - the sayings and actions of Prophet Muhammad. There is an inherent tendency in human beings towards privacy, the most important thing at home [14]. Three different layers of privacy explicitly follow privacy in a Muslim home in Indonesia. These include a) privacy between outsiders and neighbors, b) privacy between men and women, and c) privacy between family members and relatives. Privacy is achieved through visual and acoustic privacy. The optimum privacy in a traditional Muslim's home requires gender separation systems that maintain the safety of non-mahram woman (not blood-related) [15].

In Islam, the act refers to the attitude of modesty or shyness, humility, and moderation. Modesty in Islam is represented in the form of daily prayers to Allah [16]. Moslems are reminded to have a courtesy outer (physical) and mind based on the Quran and Sunnah's learning. Courtesy of Islamic Physical related to the closure of intimate body parts to protect women and men from non-mahram of every movement indecent can lead to sexual harassment or violations that are prohibited. Other physical Islamic modesty can be represented in the form of building design [17]. Highlights the importance of simplicity and space occupancy appearance in Muslim home interiors. Waste in home design is not recommended in Islam. However, Muslim occupancy can maintain the elegance and beauty of minimal design and furniture arrangement. Occupancy of a Moslem is also a place to perform and practice religious activities such as prayer, reading the Quran, or even a family funeral service. Flexibility to pray in occupancy individually, with family and friends, highlights the importance of providing internal space for this activity.

Receiving guests is an essential domestic etiquette of hospitality in Islam. Friendliness can be de- fined as a constitutionaly acceptance. It is understood closely related to acting lovingly toward strangers and sharing with others [15]. Homes in Indonesia played an important role in entertaining guests in the occupancy public, also known as the living room. It is the only part of occupancy that can be accessed directly from the main entrance. The main social activities, such as entertainment, meetings, discussions, and prayer in the congregation, take place in this area. Women are socializing in a transitional space, which is located between the living room and dining room. Food preparation is done in the kitchen.

The aims of this research are:

1. To find out whether residential with minimalist architecture meets the needs of space for Moslem family activities

2. To provide recommendations for Muslim families to adapt living in dwellings with minimalist architectural concepts

\section{METHODS}

This research used qualitative methods. This study addresses issues that require an in-depth understanding of the context of the time. The situation is concerned, naturally appropriately conducted, and following the objective conditions on the ground without manipulation and the type of data collected primarily qualitative data. The research process is among other people's observations in their everyday lives and seeks to understand the language and interpretation. This study's variable is privacy, tested in two Moselem houses as a case study [18].

Sample selection criteria are:

1. Samples were taken from the minimalist dwelling built based on the occupants' design, not from real estate development.

2. Muslim families of residents with minimalist architectural concepts are devout families carrying out Islamic religious services.

The primary data collection is done by interview and observation methods. The survey technique used is place centered mapping. Steps of the research are observing the objects of study and then make a list of the observed behavior and determine a symbol or sign sketchy behavior. The data is then based on practice in the collective experiments in the analysis to obtain conclusions behavioral tendencies. The measures undertaken in this technique are 1) Determine the place/space to be observed (object of study), 2) Viewing activity that occurs in the place of observation, and 3) Take note of the events that formed in place of observation [19]. Islamic thought as a determinant factor affects an individual's action in the built environment are analyzing from two essential directions, including 1) its effect through environmental information in the built environment; 2) its impact on the perceptual process of people to execute an action [20]. 


\section{Data analysis method are:}

1. Describe the mapping of occupant activity in the sample house plans based on zoning variables, namely privacy, modesty, and hospitality.

2. Provide recommendations on occupant activities zones so that residents can adapt to spaces in the house with a minimalist concept.

Early traditional Muslim house follows certain Islamic principles as guidelines in architectural design. As a way of life, the house should provide a complete living web that reflects the Muslims' lifestyle [3].

\section{SAMPLE HOUSES USED FOR THE STUDY}

\section{Case Study House 1 (type $70 \mathrm{~m}^{2}$ )}

In this family, good relations with nearby neighbors just greeted each other and interact socially in Islamic activities. As their habits at home like, eat, sleep, learn, cook, rest, keeping the house, interact socially, and in the morning, Mom and Dad go to work until the afternoon. The family's social circumstances met will all their needs. Due to each family member's business, they are not there to follow indigenous Minang and Java traditions' activities. Still, before traveling away, they usually prepare typical dishes of Minang family.

Opinions about this family's privacy; The clothes are not fully closed when they stay in the house, but maintain decorum if someone who is not a mahram come to visit. In terms of modesty, they spend more time in the room and worship in the mosque near their home and let guests to pray at a mosque in the area near the house because it makes them feel interfere with private spaces. In terms of hospitality, they found the home as a place of the family privacy and not for receiving guests, but they respect and serve the guests who come to visit.

\section{Case Study House 2 (type $100 \mathrm{~m}^{2}$ )}

This family has a close relations with the neighbors to communicate, maintaining social cohesion, and help each other. As their habits at home like, eat, sleep, learn, cook, rest, keeping the house, interact socially, and in the morning, father and brother went to work until late. The family's social circumstances adequately met their needs because Islam is the learning needs of their families. Indigenous Minang tradition is not applied in this family, and Islamic law.

Opinions about this family's privacy; The clothes are not fully closed when they stay in the house, but maintain decorum if someone who is not a mahram come to visit. In terms of modesty, they spend more time at the mosque worship close to home, and female family members usually spend time in the room of prayer. And in terms of hospitality, they gladly accept and serve the guests who come to visit.

\section{DISCUSSION}

Based on the reserch results, identification of areas in the house as follows:

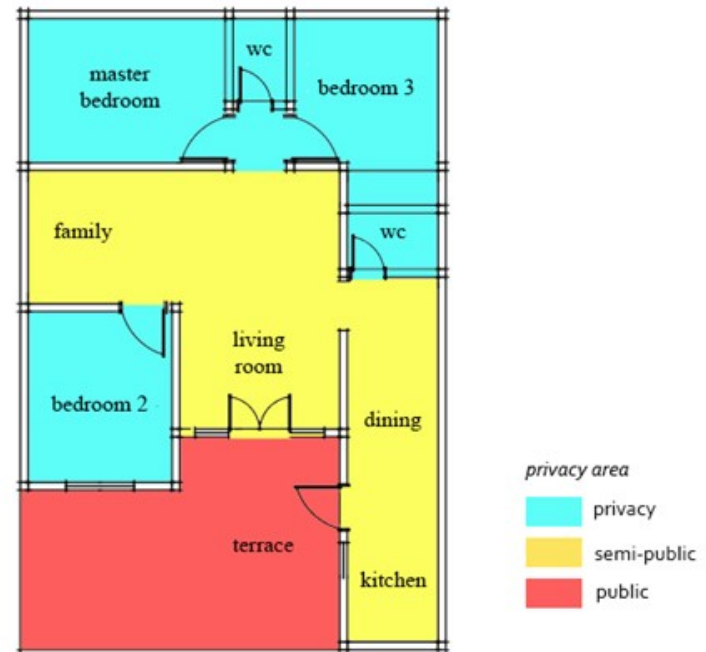

Figure 1. Identification Privacy Area in House 1

Figure 1 explains the identification of the area classification based on the privacy variable in House 1. The identification process of privacy area in Muslim occupancy in Indonesia is explicitly followed by three different layers of privacy [10]: (a) Privacy against the outside world (b). Privacy against those allowed into the house (c). Privacy among members of the household themselves.
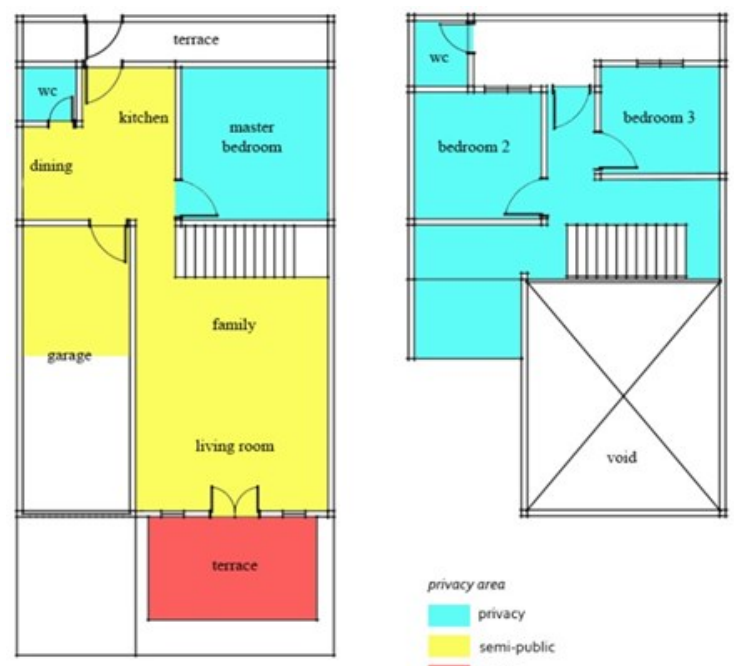

Figure 2. Identification Privacy Area in House 2

Other physical Islamic modesty can be represented in the form of building design. Figure 2 explains the identification of the area classification based on the privacy variable in House 2.

In this occupancy, there is no separation between living and family room,. To the front and rear, home occupancy has a curtain for a room divider. The 
curtains are also used as a separator of front room and kitchen room, maintaining the privacy of each room. His public bathroom area also can not be seen directly from the living room. It is divided by a curtain that provides the convenience of users.

Occupancy of a Muslim is also a place to perform and practice religious activities such as worship, study, and read the Quran. This activity is usually done in the privacy area of users including bedrooms.

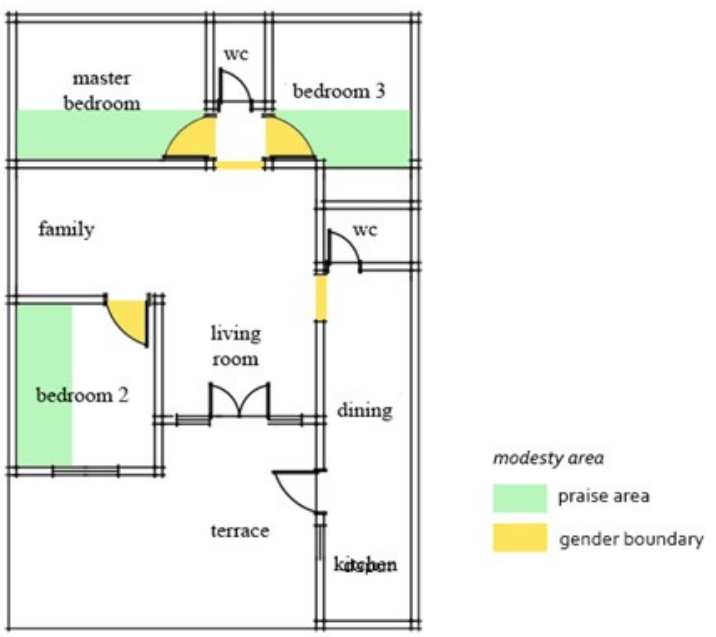

Figure 3. Identification Modesty Area in House 1
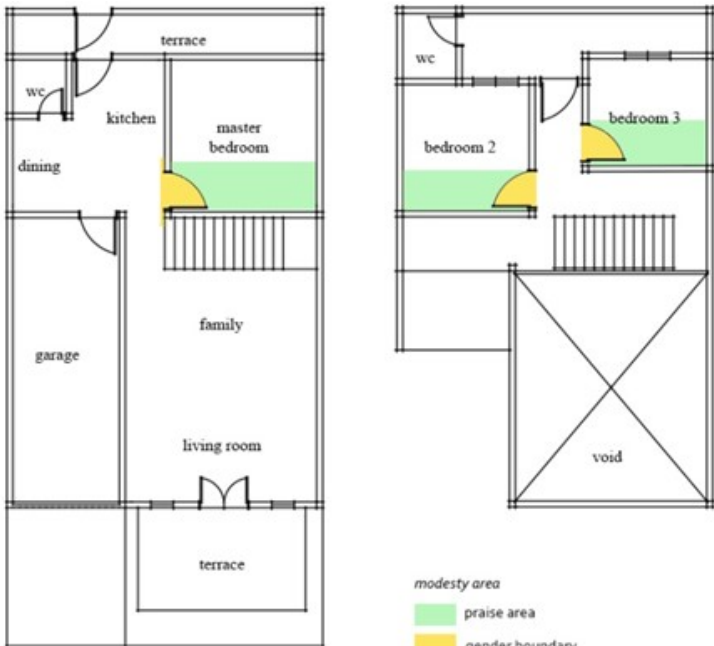

Figure 4. Identification Modesty Area in House 2

Figure 3 and Figure 4 explain the area classification's identification based on the modesty variable in House 1 and House 2. The vacancy is the etiquette in occupancy stairs. Islam recommends that honor guests who come to the dwelling. House 1 provides a front terrace to entertain male guests and a living room for female guests. If circumstances do not allow limitations, mahram's female guests will be treated in the living room. In House 2, the patio entertains male guests because of the many female members in the house. Female guests are welcome into the living room

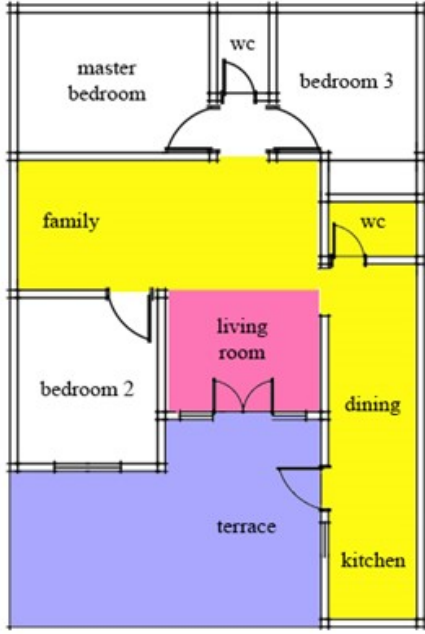

hospitality area

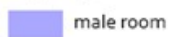

female room

receiving guest

Figure 5. Identification Hospitality Area in House 1

The matter of privacy and hospitality in Islamic culture has an impact on the formation of houses. Figure 5 and Figure 6 explain the area classification's identification based on the Hospitality variable in House 1 and House 2.

Guests will also be served by steeping drink provided by a boy or mother. Guests are welcome to use the toilet on the ground floor and other rooms such as a terrace and a large space (family room and living room) for a chat and so on. The excellent room condition looks simple because it does not use chairs and tables, just use the floor mat as a seat.
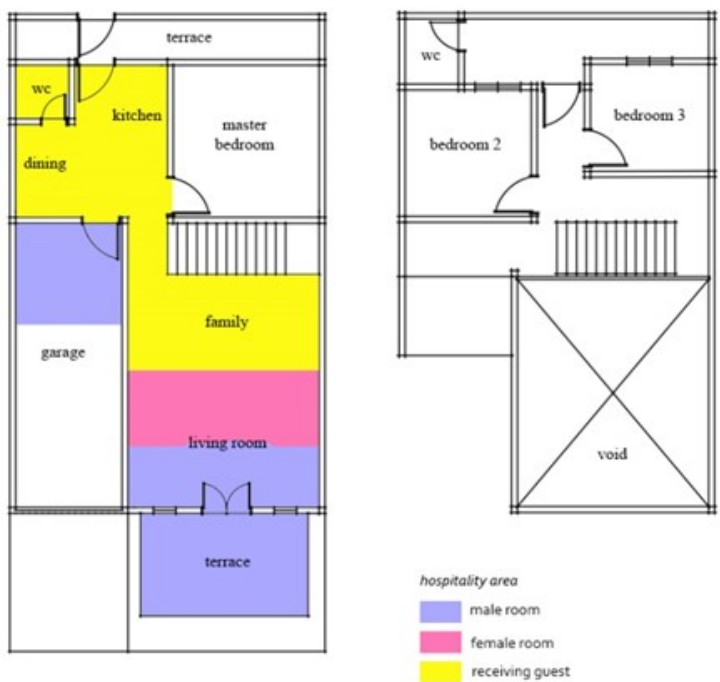

Figure 6. Identification Hospitality Area in House 2

Identification of the adaptation process carried out by residents of the house related to privacy aspects are :

- $\quad$ Selecting the furniture as boundary between public and semi-public area for the need of privacy space

- $\quad$ Disadvantages will need the family to own the room space because the number of women's rooms is not sufficient. They apply by putting

80 | Journal of Islamic Architecture, 6 (2) December 2020 
two of their daughters in one bedroom, even though it was uncomfortable. For keeping their respective privacy, they make a barrier of the curtain on the women's room and bathroom.

Identification of the adaptation process carried out by residents of the house related to modesty aspects are :

- Create a barrier of curtains in the women's room and bathroom.

- $\quad$ Each family was taught to praise in the mosque for men and praise in the house for women.

Identification of the adaptation process carried out by residents of the house related to hospitality aspects are:

- $\quad$ Receiving guests according to the conditions in which women are more welcome in the home (living room) and a man on the terrace home.

These observations used a value of $1-5$ to determine each Muslim family's adaptability in the occupied home. This assessment is made in the form of table data results that have been obtained from the interviews.

Table 1. Indicators and variables based on adaptation family

\begin{tabular}{llcc}
\hline \multirow{2}{*}{ Variables } & \multicolumn{1}{c}{ Indicator } & home $\mathbf{1}$ & home 2 \\
\hline Privacy & Security barrier & 5 & 3 \\
\cline { 2 - 4 } & Noise & 4 & 4 \\
\cline { 2 - 4 } & Aperture & 5 & 3 \\
\cline { 2 - 4 } & Gender boundary & 5 & 2 \\
\hline Modesty & The boundary of & 5 & 5 \\
& $\begin{array}{l}\text { mahram and non- } \\
\text { mahram }\end{array}$ & & \\
\cline { 2 - 4 } & Interior design & 5 & 3 \\
\cline { 2 - 4 } & Praise area & 5 & 3 \\
\hline Hospitality & Receiving guest & 5 & 4 \\
\cline { 2 - 4 } & Male room & 3 & 3 \\
\cline { 2 - 4 } & Female room & 4 & 3 \\
\hline Total & & 46 & 32 \\
\hline
\end{tabular}

\section{RECOMMENDATION}

Figures 7 and 8 are the recommendations for minimalist contemporary architectural housing in a study case 1 and 2 .

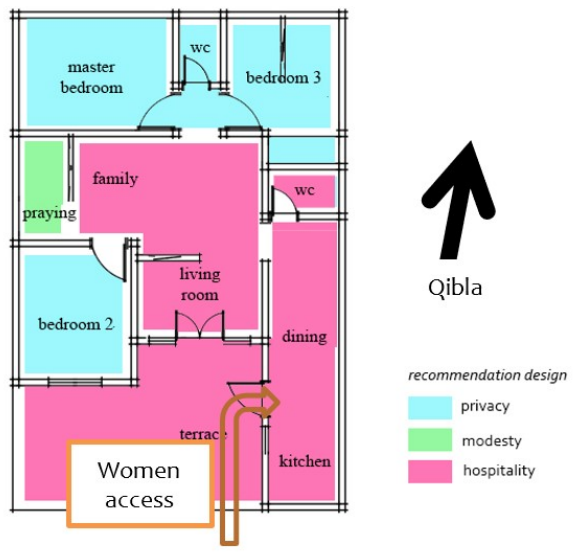

Figure 7. Recommendation for Home 1

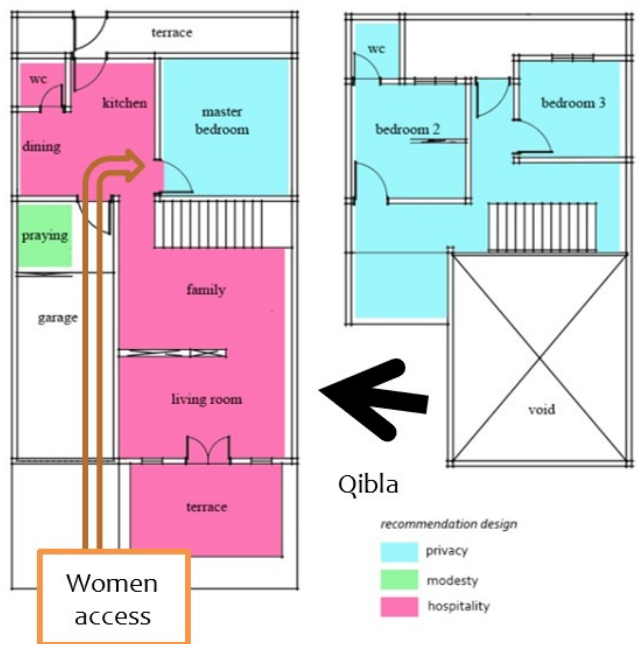

Figure 8. Recommendation for Home 2

\section{CONCLUSION}

The process of adaptation to the house's needs (privacy, modesty, and hospitality) significantly affects the calculated time. It can be fast, slow, or fail. The process of adaptation to the needs of privacy faster because each family will start by choosing these choices that will make them comfortable. The need adjustment to the modesty aspect is unsuccessful because of the limitation of space availability and each family's attitude. Process of the adaptation to the needs of hospitality is too rapid. It has become imperative for Muslims to respect his family.

The researchers also found the performance space on minimalist architecture was still not sufficient for Muslim families, such as the worship space. The praise area dimensions are too small. There is a lot of unused area on home 2, which should be maximized with good access to the house. There is no gender segregation in received guests, and home entrance is too exposed.

\section{REFERENCES}

[1] S. Malik and B. Mujahit, "Perception of House Design in Islam: Experiences from Saudi Arabia and Pakistan," Journal of Islamic Thought and Civilization, vol. 6, no. 2, pp. 53-76, 2016.

[2] V. Stevanovic, "Cultural Based Preconceptions in Aesthetics Experience of Architecture," Spatium International Review, vol. 26, pp. 2025, 2011.

[3] A. N. A. Hwaish, "Concept of The Islamic House A Case Study of The Early Moslems House," in Proceedings of 4th IASTEM International Conference, 2015.

[4] A. A. K. Khalifah, E. E. Pandelaki, and S. Rukayah, "Consumer Preference in Type of Housing Appearence Offered by Housing De- 
veloper in Semarang," Teknik, vol. 36, no. 2, pp. 91-95, 2015.

[5] A. S. Hassan, Y. Arab, and M. Ismail, "Architectural Styles and Developments of Apartments in Putrajaya, Malaysia," International Transaction Journal of Engineering, Management, \& Applied Sciences \& Technologies, vol. 4, no. 3, pp. 191-206, 2015.

[6] D. Vasilski, "On Minimalism in Architecture Space as Experience," Spatium, vol. 36, pp. 6166, 2016.

[7] C. Foye, "The Relationship Between Size of Living Space and Subjective Well-Being," Journal Hapiness Study, vol. 18, pp. 427-461, 2017.

[8] I. Altman, A. Rapoport, and J. F. Wohlwill, Human Behaviour and Environment, Advances in Theory and Research 4. Environment and Culture. New York: Plenum Press, 1980.

[9] M. R. Hidayat and K. Parman, "Trend of Islamic Dwelling in Indonesia and its Differences with Conventional Dwelling," Advances in Social Science, Education and Humanities Research, vol. 343, pp. 56-62, 2019.

[10] A. M. El-Shorbagy, "Traditional Islamic Arab House: Vocabulary and Syntax," International Journal of Civic \& Environmant Engineering, vol. 10, no. 4, pp. 15-20, 2010.

[11] H. Noorradin, "Al-fina', in Between Spaces as an Urban Design Concept: Making Public and Private Places along Streets in Islamic Cities of the Middle East," Urban design international, vol. 3, no. 1-2, pp. 65-77, 1998.

[12] T. Abu-Gaueh, "Privacy as the Basis of Architectural Planning in the Islamic Culture of Saudi Arabia," Architecture and Behaviour Journal, vol. 11, no. 3, pp. 269-288, 1995.

[13] Z. Othman, L. Buys, and R. Aird, "Observing Privacy, Modesty And Hospitality In The Home Domain: Three Case Studies of Moslem Homes in Brisbane, Australia," International Journal of Architecture Research, vol. 8, no. 3, pp. 266283, 2014.

[14] G. H. Memarian, S. M. H. T. Oljerdi, and A. M. R. Kermani, "Privacy of House in Islamic Culture: A Comparative Study of Pattern of Privacy in House in Kerman," International Journal of Architecture Engineering and Urban Planning, vol. 21, no. 2, pp. 69-78, 2011.

[15] R. Belk and R. Sobh, "Domains of privacy and hospitality in Arab Gulf homes," Journal of Islamic Marketing, vol. 2, no. 2, pp. 69-78, 2011.

[16] M. Hussain, The Five Pillars of Islam : Laying the Foundations of Devine Love and Service to Humanity. New York: Kube Publishing, 2012.

[17] H. Mortada, Traditional Islamic Principles of Built Environment. New York: Routledge, 2005.

[18] H. Babangida and H. S. Katsina, "Integrating Islamic Design Principles for achieving family privacy in Residential Architecture," Journal of Islamic Architecture, vol. 5, no. 1, pp. 9-19, 2018.

[19] Z. Othman, "Privacy, Modesty, Hospitality and the Design of Moslem Homes in Australia," Queensland University of Technology, Australia, 2016.

[20] M. H. Ahmad, M. Behrang, and D. Farimah, "Islamic Thoughts and Individuals' Actions in the Built Environment," GJAT, vol. 4, no. 2, pp. 59-70, 2014. 